10. Рапохин Н.П. Прикладная психология: учеб. пособие / Н.П. Рапохин. - М.: ИНФРА-М, 2020. - 430 c.

11. Третьякова А.Н., Полевая М.В. Психологические методы управления персоналом // Научный вестник МГИИТ. 2012. № 2 (16). С. 112-117.

12. Управленческая психология: учеб. пособие / Г.И. Колесникова [и др.]. - Ростов н/Д: Феникс, 2016. $-284 \mathrm{c}$.

13. Щербатых Ю.В. Психология труда и кадрового менеджмента в схемах и таблицах: справочное пособие / Ю.В. Щербатых. - 2-е изд., стер. - Москва: КНОРУС, 2016. - 248 с.

14. Юревич А.В. Методология и социология психологии. - М.: Изд-во «Институт психологии РАН», 2010. $-272 \mathrm{c}$.

\title{
Момот Ю.А. \\ Особенности мотивационной сферы подростков с деструктивным коммуникативным поведением в интернет пространстве
}

\author{
ГБОУВО РК КИПУ ИМЕНИ Февзи Якубова \\ (Россия, Симферополь)
}

doi: $10.18411 / \mathrm{j}-05-2021-300$

\section{Аннотация}

В статье представлено исследование, в рамках которого рассматривается направленность коммуникативного поведения, производится контент-анализ личных страниц подростков в социальных сетях, изучаются особенности мотивационной сферы пользователей, демонстрирующих в интернет-пространстве деструктивное и конструктивное коммуникативное поведение. Рассматриваются доминирующие мотивы пребывания в интернете у подростков с различной направленностью коммуникативного поведения: мотив воплощения в роль, личного пространства, репликации, мотив вклада и мотив обозначенного присутствия. А также описана выраженность негативной коммуникативной установки у подростков с той или иной направленностью коммуникативного поведения.

Ключевые слова: деструктивное коммуникативное поведение, конструктивное коммуникативное поведение, мотивы, установки, направленность, подростки, интернет-пространство.

\section{Abstract}

The article presents a study in which the direction of communicative behavior is considered, a content analysis of the personal pages of adolescents in social networks is carried out, the features of the motivational sphere of users who demonstrate destructive and constructive communicative behavior in the Internet space are studied. The dominant motives of being on the Internet among adolescents with different orientations of communicative behavior are considered: the motive of incarnation in a role, personal space, replication, the motive of contribution and the motive of the indicated presence. It also describes the severity of the negative communicative attitude in adolescents with one or another orientation of communicative behavior.

Keywords: destructive communicative behavior, constructive communicative behavior, motives, attitudes, orientation, adolescents, Internet-space.

Цифровое пространство в 21 веке является неотъемлемой частью жизни каждого человека. Благодаря современным технологиям появились новые возможности, в том числе возможности коммуникации. Это в свою очередь, непременно, ведет к развитию особого культурного пространства и оказывает влияние на формирование человека как личности. [1] То есть интернет отнюдь не сводится к пониманию его как пространства, предоставляющего информацию. Интернет является пространством со своими законами и правилами, где пользователи активно взаимодействуют, осуществляют 
различную деятельность в соответствии со своими мотивами, потребностями и интересами. [2]. Под воздействием Интернета происходят изменения в ценностных ориентациях личности, формируются новые по своему содержанию, качеству виды досуговой деятельности, появляются новые практики, стратегии поведения» [6]. Особенностью виртуального пространства является отсутствие социального контроля, практически неограниченная свобода, построение личности через языковые формы, возможность анонимности [3].

В настоящее время в интернет-пространстве реализуется целый спектр целей, ценностей, новых видов деятельности (деловые, коммуникативные, образовательные, досуговые) и форм взаимодействия, что говорит о том, что виртуальное пространство стало новой средой для социализации личности. Это свидетельствует об актуальности исследования поведения, в том числе непосредственно коммуникативного поведения в интернете. Ведь нарушение правил и норм коммуникативного поведения может навредить другим пользователям, поэтому существует необходимость определения мотивов и установок, лежащих в основе деструктивного коммуникативного поведения.

Для изучения особенностей мотивации коммуникативного поведения было проведено эмпирическое исследование, в котором приняли участие пользователи Интернета. Они привлекались на основе первичного анализа комментариев и обсуждений различного контента в группах и сообществах социальных сетей (Вконтакте и Instagram). Отбор респондентов основывался на таких параметрах, как: использование ненормативной лексики, оскорбление личности, деструктивная критика, насмешки - отсутствие параметров (нормативное коммуникативное поведение) наличие (деструктивное коммуникативное поведение). Таким образом, были определены выборки с конструктивным и деструктивным коммуникативным поведением. Для подтверждения первичного предположения о направленности поведения, основанного на анализе комментариев пользователей, им была предложена авторская анкета «Выявление пользователей с нормативным и деструктивным коммуникативным поведением», которая состоит из двух блоков. Первый блок включает общие вопросы, которые позволяют прояснить пол, возраст, время, проводимое в Интернете. Второй блок включает вопросы, ориентированные на выявление отношения к деструктивным аспектам коммуникации: нарушению норм, использованию нецензурных выражений, оскорблений и т.д. В соответствии с полученными результатами, подтверждается первичное распределение подростков, выделяется выборка с нормативным (23 человека) и деструктивным (21 челок) коммуникативным поведением.

Следующим этапом исследования является контент-анализ личных страниц пользователей в социальных сетях. Анализ проведен в соответствии с выделенными категориями и единицами счета. Наиболее важными параметрами в данном случае является анонимность, закрытый профиль, демонстрация личных фотографий, представленность настоящим именем или «ником», а также публикация неподобающего контента (пропаганда вредных привычек, фашизма, терроризма), наличие подписок на соответствующие сообщества, троллинг, a также непосредственное общение. Оказалось, 38\% подростков, представляющих выборку с деструктивным коммуникативным поведением, имеют закрытый профиль, 81\% респондентов предпочитают не публиковать личные фото, 42\% используют «ники», $38 \%$ склонны к демонстрации деструктивного контента, более $90 \%$ используют нецензурную лексику и процессе коммуникации могут оскорбить, унизить, раскритиковать другого человека. У выборки с нормативным коммуникативным поведением, такие проявления не отмечены, 13\% используют ненормативную лексику, только у $9 \%$ ограничен доступ к странице, у 13\% настоящее имя заменяет «ник», у $72 \%$ фотогалерея включает личные фотографии. 
Коммуникативное поведение неразрывно связано с собственным представлением о себе, поэтому респондентам была предложена методика М. Куна и Т. Макпартланда «Кто я?», данном исследовании использована ее модификация «Кто я в интернете?». Результаты, полученных в результате ответов, данных подростками с деструктивной направленностью коммуникативного поведения, говорят о большей выраженности «Социального Я» $(73 \%)$ и «Виртуального Я» $(74 \%)$, что говорит о формальном обозначении ролей, низком уровне рефлексивности. У пользователей из противоположной выборки напротив более выраженно «Рефлексивное Я» (67\% против $33 \%)$, «Перспективное Я» (70\% против 19\%), «Коммуникативное Я» (68\% против 41\%), что говорит о способности к анализу своего поведения, себя в целом, «Перспективное я», характеризует личность как стремящуюся к достижениям, самореализации, развитию [5]. Кроме того анализ ответов «Виртуального я» позволил выделить распределение пользователей в соответствие с приписываемыми ими интернет-ролями. Так подростки с деструктивным коммуникативным поведением чаще, чем подростки с конструктивным поведение приписывают себе следующие роли: «аноним» (39\% против 10\%), «комментатор» (58\% против 34\%), «игрок» (45\% против 31\%). Однако $36 \%$ пользователей с нормативным поведением представляют себя «блогерами» и только $12 \%$ из другой выборки отмечают данную роль. Таким образом определены особенности «Образа я» и выделены свойственные каждой из выборок роли, играемые в виртуальном пространстве.

Для изучения мотивов пребывания в Интернете был использован опросник «Личность в виртуальном пространстве». Результаты отражены на рисунке 1.

\begin{tabular}{|c|c|c|c|c|c|}
\hline \multirow[t]{2}{*}{ Выборка } & $\begin{array}{l}\text { Мотив } \\
\text { вклада }\end{array}$ & $\begin{array}{l}\text { Мотив } \\
\text { реплика } \\
\text { цин }\end{array}$ & $\begin{array}{l}\text { Мотнв } \\
\text { лнчного } \\
\text { простра } \\
\text { нства }\end{array}$ & $\begin{array}{l}\text { Мотнв } \\
\text { воплоше } \\
\text { ния в } \\
\text { роль }\end{array}$ & $\begin{array}{l}\text { Мотнв } \\
\text { обозна } \\
\text { ченног } \\
\text { о } \\
\text { присут } \\
\text { ствия }\end{array}$ \\
\hline & \multicolumn{3}{|c|}{ Творческая мотивация } & \multicolumn{2}{|c|}{$\begin{array}{c}\text { Потребительская } \\
\text { мотивация }\end{array}$} \\
\hline $\begin{array}{l}\text { Подросткн с деструктнвным } \\
\text { коммуннкативным поведеннем }\end{array}$ & $5 \%$ & $62 \%$ & $33 \%$ & $81 \%$ & $19 \%$ \\
\hline $\begin{array}{l}\text { Подросткн с норматнвным } \\
\text { коммуникативным поведеннем }\end{array}$ & $83 \%$ & $9 \%$ & $9 \%$ & $9 \%$ & $91 \%$ \\
\hline
\end{tabular}

Рисунок 1. Доминирующие мотивы пребывания а Интернете

Как видно из таблицы, у пользователей с нормативным коммуникативным поведением доминирует мотив вклада (публикация и распространение интересующего контента), мотив обозначенного присутствия (стремление к общению с большим количеством пользователей одновременно, присущ деловой стиль общения). А у выборки с деструктивным коммуникативным поведением доминирует мотив воплощения роль, мотив репликации и мотив личного пространства. Это говорит о стремлении к созданию личных страниц, которые зачастую закрыты от других пользователей, проживании нескольких «жизней» и ролей одновременно. Кроме того, было определено, что подростки с деструктивным коммуникативным поведением имеют соответствующую направленность интернет-социализации (деструктивную), что говорит о стремлении к нарушению норм взаимодействия в виртуальном пространстве, конфликтном поведении, а респонденты из противоположной выборки имеют 
конструктивную направленность и не склонны к подобным проявлениям. В выборке с деструктивной направленностью более выражена вовлеченность, они более остро ощущают потребность в Интернете, свою принадлежность к нему, мотивированы проводить там больше времени. Что касается такого параметра как виртуальность, он выражен как у выборки с нормативной, так и у выборки с деструктивной направленности и говорит о значимости интернета для всех пользователей [4]. Однако, в зависимости от направленности, подростки демонстрируют то или иной контент, поведение, и особенности взаимодействия с другими. Данные различия проверены с помощью U-критерия Манна-Уитни и определены как достоверные.

Кроме того определено, что пользователи с деструктивной направленностью имеют общую негативную коммуникативную установку и соответственно строят свое взаимодействие на основе данной установки. Они чаще проявляют открытую жестокость, брюзжание, а также завуалированную жестокость в отношении других пользователей (склонность к «подсиживанию», зависти, негативной критике и оценке людей ,отсутствует желание помогать другим). Интересным является тот факт, что по шкале «Обоснованный негативизм» более высокие показатели имеют пользователи с нормативным коммуникативным поведением, хотя они менее склонны к выражению как открытой, так и завуалированной жестокости в отношении к людям. Данные различия установлены при помощи методики «Диагностика коммуникативной установки» В.В. Бойко, а также установлены достоверные различия с помощью Uкритерия Манна-Уитни. Различия существенны по таким шкалам как: завуалированная жестокость, открытая жестокость, брюзжание и конечно по шкале, диагностирующей наличие и уровень негативной коммуникативной установки.

$$
* * *
$$

1. Войскунский А.Е. Психологические исследования феномена интернет-аддикции / А.Е. Войскунский // Тезисы докладов 2-й Российской конференции по экологической психологии. Москва: Экопсицентр РОСС, 2000. - С. 251- 253

2. Волкова Т. Г. Анализ образа Я как продукта самосознания личности / Т.Г.Волкова // Современная психология: материалы междунар. науч. Конф.-2012.- С. 1- 4

3. Королева Н.Н. Влияние коммуникации в сети Интернет на личностные особенности пользователей [Текст] / Н.Н. Королева// Известия Российского государственного педагогического университета им. Герцена - 2004.-№9 - С. 168-178

4. Лучинкина А. И. Анализ девиантного направления интернет-социализации [Электронный ресурс] / А. И. Лучинкина // Учёные записки: электронный научный журнал Курского государственного

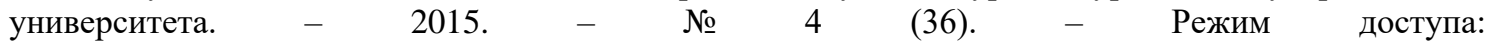
https://cyberleninka.ru/article/n/analizdeviantnogo-napravleniya-internet-sotsializatsii.

5. Румянцева, Т.В. Тест «Кто Я?» (М.Кун, Т.Макпартленд; модификация Т.В.Румянцевой) [Текст] / Румянцева Т.В.// Психологическое консультирование: диагностика отношений в паре - СПб., 2006. - C.82-103.

6. Соломина Л.Ю. Методические аспекты психологического исследования интернет-зависимости /Л.Ю. Соломина// Царскосельские чтения. - 2011.- Т.3.№15.- С.331-336

\section{Родермель Т.А., Сычева В.С. Психологическое консультирование методом транзактного анализа}

Сургутский государственный университет (Россия, Сургут)

doi: $10.18411 / 1 j-05-2021-301$

\section{Аннотация}

В данной статье рассматриваются теоретические основы понятия «психологическое консультирование», в том числе, проанализирован процесс психотерапии в психологической консультации, а также представлен более подробно метод транзактного анализа в работе психолога. В данной статье, мы можем видеть не 